\title{
Intratesticular cellular angiofibroma - a rare benign tumour: case report and literature review
}

\author{
Tomasz Piecha ${ }^{1}$, Agnieszka Powała ${ }^{2}$, Bolesław Kuzaka ${ }^{1}$
}

Cellular angiofibroma is a rare and benign tumour of mesenchymal origin. Within a microscopic image, two main cell populations are typically observed: spindle-shaped cells and blood vessels; both of which are sometimes accompanied by atypical liposarcoma-like cells.

We present a case of a 31-year old male admitted to the Department of Urology because of a solid mass being present in the left testis. The patient underwent radical orchidectomy through the inguinal canal. Microscopic examination demonstrated an intratesticular cellular angiofibroma. During a two-year follow-up, there were no signs observed of any metastases nor disease recurrence.

Intratesticular localisation of cellular angiofibroma has never been previously reported. Benign tumours of the testis are rare, but an awareness of this phenomenon may reduce the number of unnecessary orchidectomies, thereby increasing the rate of organ-sparing surgery.

NOWOTWORY J Oncol 2017; 67, 3: 215-219

Key words: benign tumour, cellular angiofibroma, intratesticular localization

\section{Introduction}

Cellular angiofibroma, also known as an angiomyofibroblastoma-like tumour, is a rare and benign tumour that was first described in 1997 by Nucci et al. [1]. By and large under microscopic investigation, the tumour consists of two main elements: spindle-shaped cells and blood vessels that are distributed in a chaotic manner [1,2]. The original study concerned four cases of a vulva tumour in middle-aged women. This neoplasm was also subsequently described in males [2]. Cellular angiofibroma has been previously identified at different localisations, however to date, there has been no evidence of any authentic intratesticular development.

This study reports a case of a benign intratesticular tumour with the pathological characteristics of cellular angiofibroma.

\section{Case report}

A thirty-one year old man was admitted to the Urology Department because a solid mass had been found in the left testis. This lesion had been detected incidentally during scrotal ultrasonography which was performed during the diagnosis of epididymitis. Ultrasound examination revealed a solid mass with dimensions of $12 \times 11 \times 8 \mathrm{~mm}$ in the lower-lateral region of the left testicle (Fig. 1). The lesion was situated intratesticularly, approximately $2 \mathrm{~mm}$ from the tunica albuginea. In the Colour Doppler image presentation, an intense blood flow was detected inside the tumour (Fig. 2). On physical examination, a palpable tumour was not present. Laboratory tests showed a minor increased level of alpha-fetoprotein to $9 \mathrm{ng} / \mathrm{mL}$ (normal range 0-7 ng/mL). Other laboratory tests, including testicular cancer markers (i.e. beta-human chorionic gonadotropin and lactate dehydrogenase), were within reference ranges. Upon chest X-ray, metastatic lesions were not detected. The patient was qualified for a left radical orchidectomy through the inguinal canal. Intraoperatively, no macroscopic lesions in the left testis were observed.

Pathological examination revealed a gray-brown intratesticular tumour, size $12 \times 10 \times 8 \mathrm{~mm}$, which was situated

\footnotetext{
${ }^{1}$ Department of General, Oncological and Functional Urology, Medical University of Warsaw, Poland

${ }^{2}$ Department of Pathomorphology, Medical University of Warsaw, Poland
} 


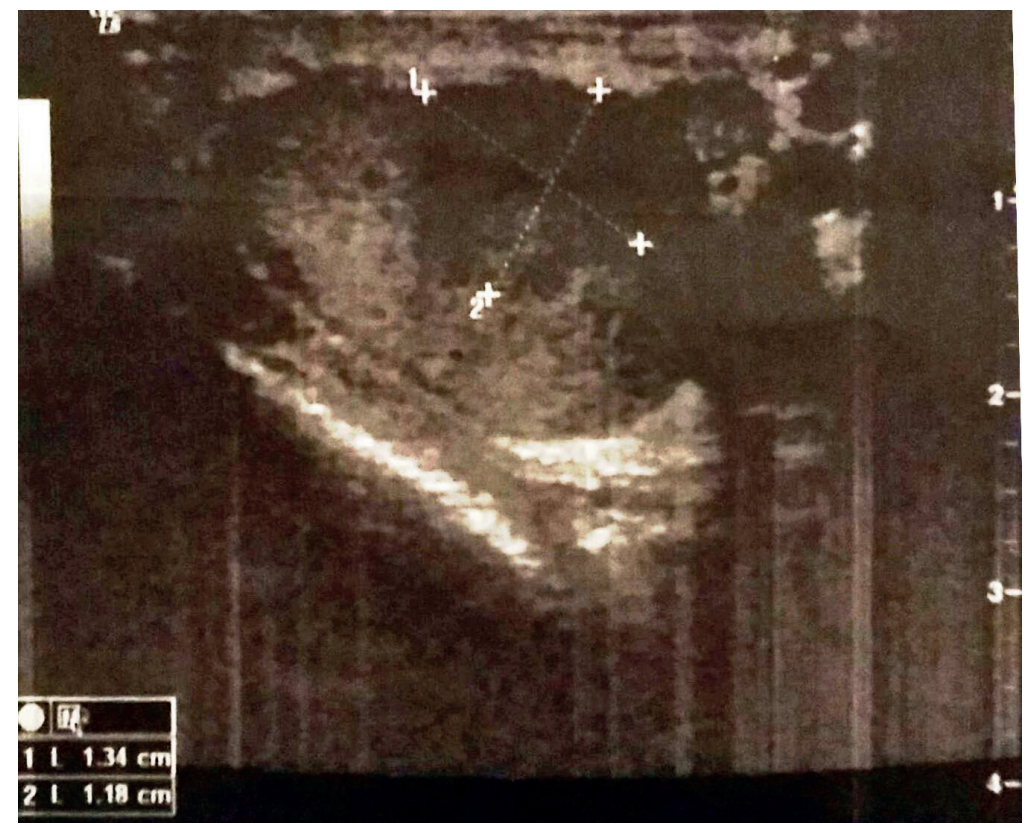

Figure 1. Ultrasound image of a hypoechoic mass, $12 \times 11 \times 8 \mathrm{~mm}$, in the lower lateral region of the left testicle

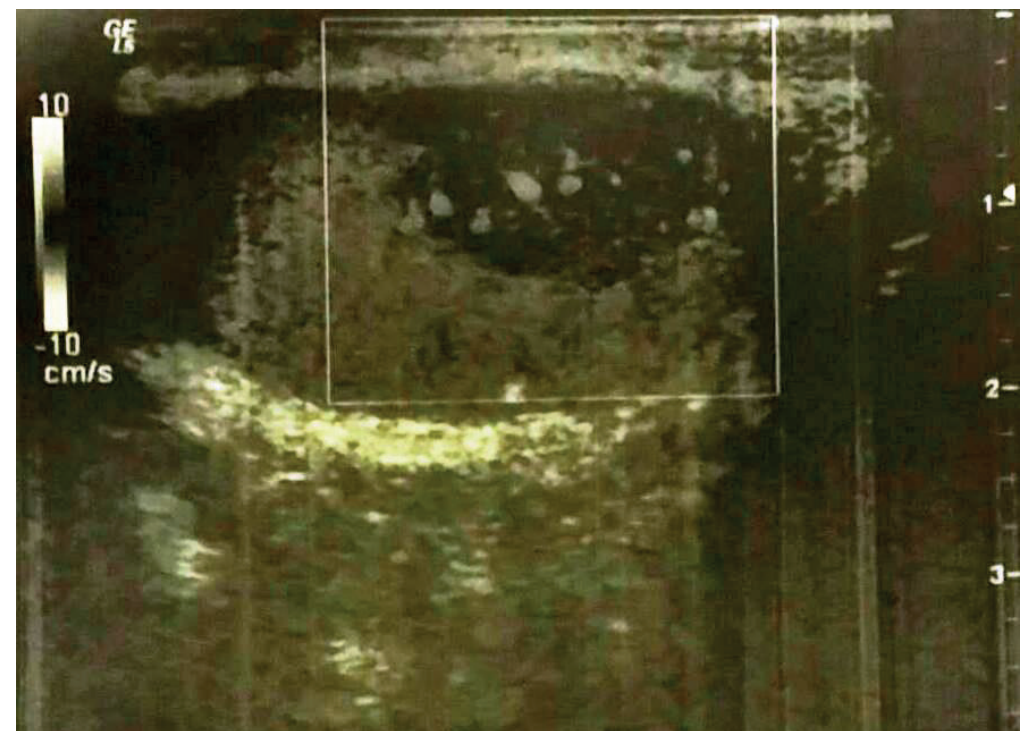

Figure 2. Color Doppler image presentation of testicular mass. Strongly increased blood flow observed inside lesion

$5 \mathrm{~mm}$ from the tunica albuginea. Microscopic investigation found spindle-shaped cells, abundant blood vessels and reactive changes. These features were consistent with the characteristics of cellular angiofibroma (Figs. 3-5).

The postoperative course was without any complications. During the two-year follow-up, no signs of recurrence nor metastasis were observed

\section{Discussion}

The vast majority of testicular neoplasms are germ cell tumours, which account for approximately $90-95 \%$ of reported cases. Intratesticular tumours are seldom of mesen- chymal origin, which constitute up to $2-4 \%$ of neoplasms; most of these being Leydig cell and Sertoli cell lesions [3]. Epidemiological data clearly demonstrates that the majority of intratesticular masses represent malignant neoplasms. This situation has resulted in establishing radical orchidectomy, via the inguinal canal, as the treatment of choice for intratesticular tumours. Benign testicular tumours are extremely rare, compared to paratesticular lesions, where benign neoplasms commonly occur [4]. A major problem in preoperatively differentiating between benign and malignant tumours is a lack of reliable imaging studies; i.e. scrotal ultrasound examination, computed tomography or 


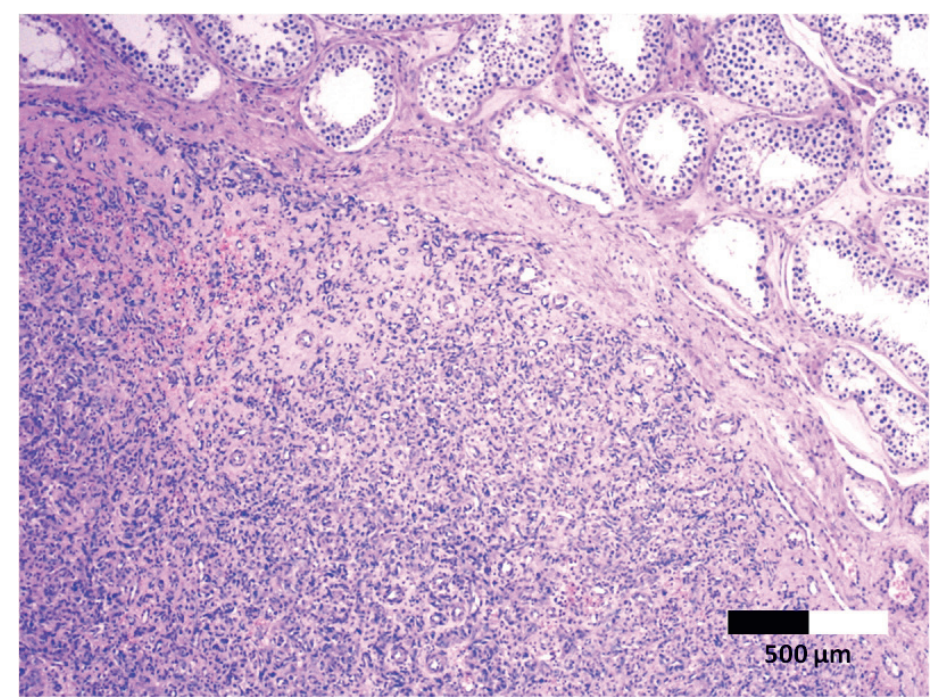

Figure 3. Intratesticular Cellular Angiofibroma microscopic image at mag. $\times 40$. Hemtoxilin-eosin staining. At low magnification, multiple cells and small blood vessels with a uniform distribution are visible

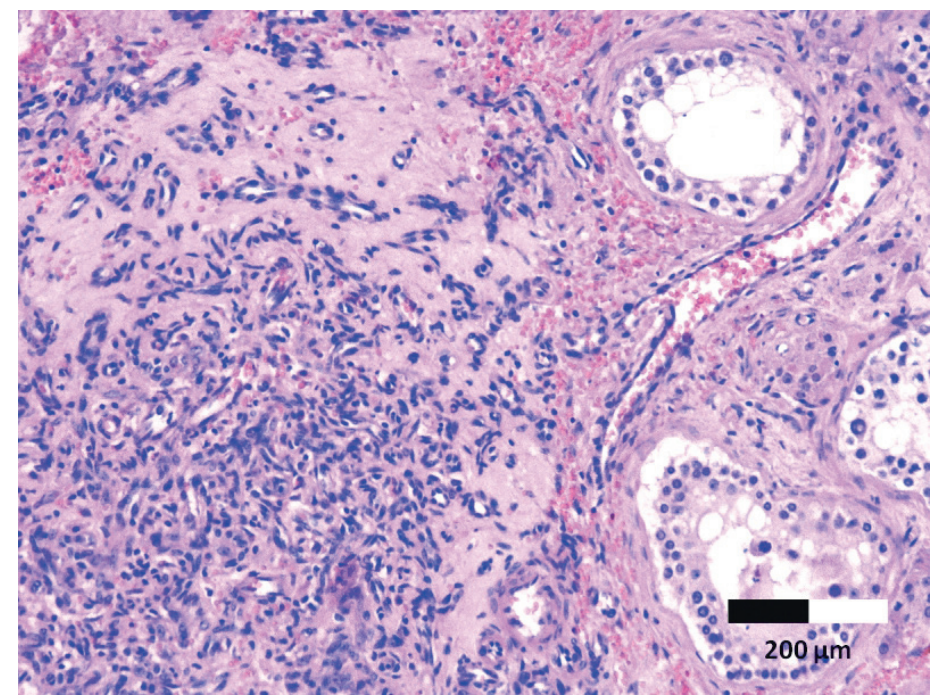

Figure 4. Intratesticular Cellular Angiofibroma microscopic image at mag. $\times 100$. Hematoxilin-eosin staining. A clear boundary between tumor tissue and testicular tissue is apparent. Significantly increased intratumor cellularity with characteristic spindle-shaped cells observed

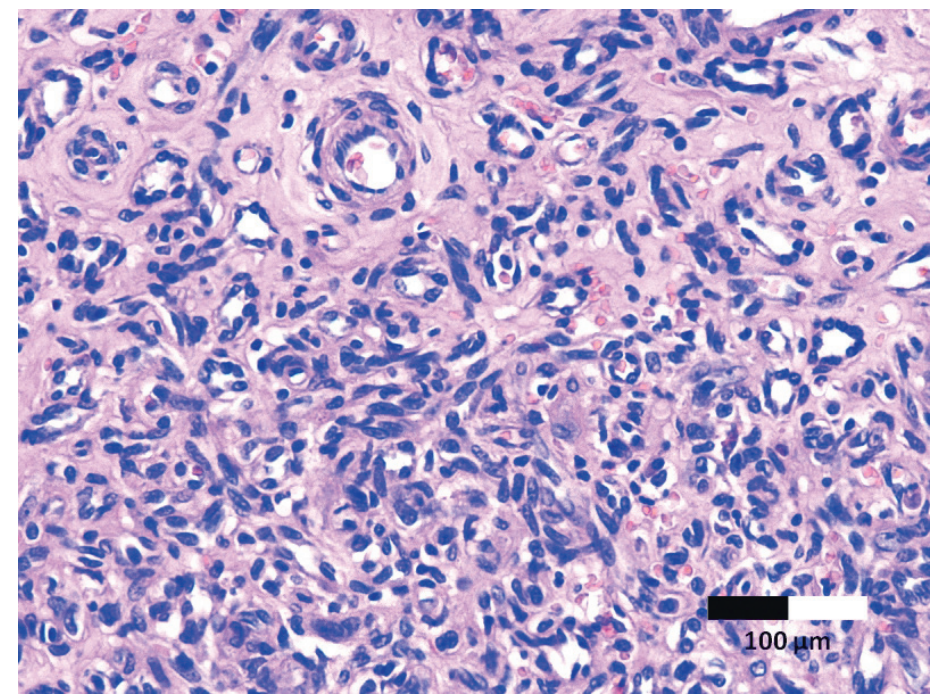

Figure 5. Intratesticular Cellular Angiofibroma microscopic image at mag. $\times 200$. Hematoxilin-eosin staining. Multiple spindle shaped cells with a uniform, pale cytoplasm are present. Abundant medium- and hyalinized thick-walled blood vessels observed 
Table I. Extragenital locations of cellular angiofibroma

\begin{tabular}{ll}
\hline Intermuscular spatium of the right thigh & Zhano M. et al. [13] \\
Paravertebral region of the neck & Zhano M. et al. [13] \\
Prostate & Wyn I. [6] \\
Oral mucosa & Eversole L. [14] \\
Cervix uteri & Babala P. et al. [15] \\
Elbow & Omori Y. et al. [7] \\
Subcutaneous tissue of the chest & Garijo M. et al. [16] \\
Minor pelvis & Iwasa Y. et al. [17] \\
Anus & Iwasa Y. et al. [17] \\
Trunk & Iwasa Y. et al. [17] \\
Retroperitoneum & Iwasa Y. et al. [17], \\
& Mandato V. et al. [18] \\
Left hip & Chen E. et al. [9] \\
Knee & Flucke U. et al. [5] \\
Left hypochondrium & Val-Bernal J. et al. [19] \\
\hline
\end{tabular}

magnetic resonance imagining do not allow conclusions to be drawn about the biological nature of the tumour. Nevertheless, a routine scrotal ultrasound has considerable accuracy for confirming the presence of a pathological mass and can also specify the location of the tumour, especially in distinguishing between intratesticular and paratesticular localisations [4].

Cellular angiofibroma (CAF), also known as angiomyofibroblastoma-like tumour, is a rare and benign neoplasm of mesenchymal origin. CAF is mainly found in patients aged over 40 years, which is typically localised in the vulva of women and in the scrotum and groin in men [5]. The published literature however describes several case reports of CAF found in unusual locations, such as the prostate or elbow [6, 7]. Other described locations are listed in Table I. Usually described neoplasms are encapsulated and situated in superficial tissues [8]. Cellular angiofibroma is microscopically characterised by mesenchymal spindle-shaped cells, thick-walled blood vessels of small and medium diameter and intracellular substance. The total absence of any normal tissue architecture is noticeable $[1,5]$. Some researchers suggest that CAF may be derived from perivascular stem cells, which normally differentiate into myofibroblasts or adipocytes [5, 9]. Genetic mutation has been described in CAF cells. Studies have observed deletion of the $13 q 14$ region, which encodes RB1 and FOXO1 genes. This may indicate a genetic similarity to spindle-cell lipomas and mammary-type fibroblastomas [10]. Atypical cells resembling well-differentiated liposarcoma cells or pleomorphic liposarcoma cells occur quite frequently, which is observed in microscopic images of cellular angiofibroma. Nonetheless, the presence of such populations does not alter the course of treatment nor of the overall prognosis. Moreover, in no reported cases have there been any clinical features of malignancy or of poor outcome [9].

Cellular angiofibroma is a pathologically and clinically benign tumour, and the treatment of choice is surgical excision [9]. All of such described cases have a good clinical outcome; infiltration or metastatic changes have not been observed $[8,11]$. Only a single study reporting local recurrence six months after CAF excision has been published [12].

The aim of this study is to thus spread knowledge on the occurrence of benign testicular tumours. It seems to us that through such awareness, it is possible to at least in part avoid unnecessary orchidectomies. In our opinion, for low risk cases where testicular cancer markers are within reference ranges, the use of intraoperative pathological examination may result in a wider application of organ-sparing surgery.

\section{Conflict of interest: none declared}

\section{Bolesław Kuzaka, MD, PhD}

Department of General, Oncological and Functional Urology

Medical University of Warsaw

W. Lindleya 4, 02-005 Warsaw, Poland

e-mail:boleslaw.kuzaka@wum.edu.pl

Received: 31 Mar 2016

Accepted: 10 Mar 2017

\section{References}

1. Nucci MR, Granter SR, Fletcher CD. Cellular angiofibroma: a benign neoplasm distinct from angiomyofibroblastoma and spindle cell lipoma. Am J Surg Pathol 1997; 21: 636-644.

2. Laskin WB, Fetsch JF, Mostofi FK. Angiomyofibroblastomalike tumor of the male genital tract: analysis of 11 cases with comparison to female angiomyofibroblastoma and spindle cell lipoma. Am J Surg Pathol 1998; 22: 6-16.

3. La Vecchia C, Bosetti C, Lucchini F et al. Cancer mortality in Europe, 2000-2004, and an overview of trends since 1975. Ann Oncol 2010; 21: 1323-1360.

4. Park SB, Lee WC, Kim JK et al. Imaging features of benign solid testicular and paratesticular lesions. Eur Radiol 2011; 21: 2226-2234.

5. Flucke U, van Krieken JH, Mentzel T. Cellular angiofibroma: analysis of 25 cases emphasizing its relationship to spindle cell lipoma and mammary-type myofibroblastoma. Modern Pathol 2011; 24: 82-89.

6. Wyn I, Debiec-Rychter M, Van Cleynenbreugel B et al. Cellular angiofibroma of the prostate: a rare tumor in an unusual location. Case Rep Pathol 2014; 2014: 871530.

7. Omori $Y$, Saeki $\mathrm{H}$, Ito $\mathrm{K}$ et al. Extragenital subcutaneous cellular angiofibroma of the elbow. J Eur Acad Dermatol Venereol 2014; 28: 828-830.

8. Mandato VD, Santagni S, Cavazza A et al. Cellular angiofibroma in women: a review of the literature. Diagn Pathol 2015; 10: 114.

9. Chen $\mathrm{E}$, Fletcher CD. Cellular angiofibroma with atypia or sarcomatous transformation: clinicopathologic analysis of 13 cases. Am J Surg Pathol 2010; 34: 707-714.

10. Magro G, Righi A, Caltabiano R et al. Vulvovaginal angiomyofibroblastomas: morphologic, immunohistochemical, and fluorescence in situ hybridization analysis for deletion of $13 q 14$ region. Human Pathol 2014; 45: 1647-1655.

11. Khmou M, Lamalmi N, Malihy A et al. Cellular angiofibroma of the vulva: a poorly known entity, a case report and literature review. $B M C$ Clin Pathol 2016; 16: 8

12. McCluggage WG, Perenyei M, Irwin ST. Recurrent cellular angiofibroma of the vulva. J Clin Pathol 2002; 55: 477-479.

13. Zhao M, Sun K, Li C et al. Angiofibroma of soft tissue: clinicopathologic study of 2 cases of a recently characterized benign soft tissue tumor. Int J Clin Exp Pathol 2013; 6: 2208-2215.eCollection 2013. 
14. Eversole LR. Cellular angiofibroma of oral mucosa: report of two cases. Head Neck Pathol 2009; 3: 136-139.

15. Babala P, Biro C, Klacko M et al. Angiomyofibroblastoma of the cervix uteri: a case report. Klin Onkol 2011; 24: 133-136.

16. Garijo MF, Val-Bernal JF. Extravulvar subcutaneous cellular angiofibroma. J Cutan Pathol 1998; 25: 327-332.
17. Iwasa Y, Fletcher CD. Cellular angiofibroma: clinicopathologic and immunohistochemical analysis of 51 cases. Am J Surg Pathol 2004; 28: 1426-1435.

18. Mandato VD, Aguzzoli L, Cavazza A et al. Coxalgia? Call the gynecologist. J Minim Invasive Gynecol 2015; 22: 663-667.

19. Val-Bernal JF, Rubio S, Garijo MF et al. Extragenital subcutaneous cellular angiofibroma. Case report. APMIS 2007; 115: 254-258. 